\title{
Aerobic Catalytic Oxidation of Cyclohexene over TiZrCo Catalysts
}

\author{
Tong Liu ${ }^{1,2,3}$, Haiyang Cheng ${ }^{1,2, *}$, Weiwei Lin ${ }^{1,2}$, Chao Zhang ${ }^{1,2}$, Yancun $\mathrm{Yu}^{1,2}$ and \\ Fengyu Zhao ${ }^{1,2, *}$ \\ 1 State Key Laboratory of Electroanalytical Chemistry, Changchun Institute of Applied Chemistry, \\ Chinese Academy of Sciences, Changchun 130022, China; liutong@ciac.ac.cn (T.L.); linwei@ciac.ac.cn (W.L.); \\ czhang@ciac.ac.cn (C.Z.); yuyc@ciac.ac.cn (Y.Y.) \\ 2 Laboratory of Green Chemistry and Process, Changchun Institute of Applied Chemistry, \\ Chinese Academy of Sciences, Changchun 130022, China \\ 3 University of Chinese Academy of Sciences, Beijing 100049, China \\ * Correspondence: hycyl@ciac.ac.cn (H.C.); zhaofy@ciac.ac.cn (F.Z.); \\ Tel.: +86-431-8526-2454 (H.C.); Tel./Fax: +86-431-8526-2410 (F.Z.)
}

Academic Editor: Michalis Konsolakis

Received: 8 December 2015; Accepted: 12 January 2016; Published: 29 January 2016

\begin{abstract}
The aerobic oxidation of hydrocarbon is of great significance from the viewpoints of both fundamental and industry studies as it can transfer the petrochemical feedstock into valuable chemicals. In this work, we investigated the aerobic oxidation of cyclohexene over TiZrCo catalysts, in which 2-cyclohexen-1-one was produced with a high selectivity of $57.6 \%$ at a conversion of $92.2 \%$, which are comparable to the best results reported for the aerobic oxidation of cyclohexene over heterogeneous catalysts. The influences of kinds of solvent, substrate concentration and reaction temperature were evaluated. Moreover, the catalytic performance of the TiZrCo catalyst and the main catalytic active species were also discussed. The results of SEM, XRD and XPS suggested that the surface $\mathrm{CoO}$ and $\mathrm{Co}_{3} \mathrm{O}_{4}$ species are the catalytic active species and contribute to the high activity and selectivity in the present cyclohexene oxidation. The present catalytic system should have wide applications in the aerobic oxidation of hydrocarbons.
\end{abstract}

Keywords: aerobic oxidation; heterogeneous catalyst; cyclohexene; TiZrCo

\section{Introduction}

The selective oxidation of hydrocarbon is of great importance in the chemical industry, and the oxidation of alkenes to value-added chemicals has been paid more attention [1-4]. For example, 2-cyclohexen-1-one, which can be produced from oxidation of the $\mathrm{C}-\mathrm{H}$ bond at the allylic site of cyclohexene, is one of the important fine chemicals because it is widely used in the manufacture of perfumes, pharmaceuticals, dyestuff and agrochemicals [5-7]. However, the yield of 2-cyclohexen-1-one produced from cyclohexene oxidation is quite low due to the existence of two active sites ( $\mathrm{C}-\mathrm{H}$ and $\mathrm{C}=\mathrm{C}$ bond) on the cyclohexene molecule [8]. Thus, it is still a great challenge to enhance the selectivity of 2-cyclohexen-1-one by designing an efficient catalyst. For oxidation of cyclohexene, the traditional oxidants are iodosylbenzene, sodium hypochlorite, chromium trioxide, t-butyl hydroperoxide, $\mathrm{H}_{2} \mathrm{O}_{2}$, etc. These strong oxidants can improve the oxidation rate and increase the yield of product, but they are expensive and harmful to the environment. Therefore, developing a green oxidation process is of importance in view of the academic research and industrial application. Recently, the oxidation with molecular oxygen as an oxidant has received much attention as it is a cheap, abundant and environmentally benign process and some achievements have been obtained [9-13]. For example, the ionic liquids with metal chelate anion $\left[\mathrm{C}_{10} \mathrm{mim}\right]\left[\mathrm{Co}\left(\mathrm{F}_{6} \text {-acac }\right)_{3}\right]$ exhibited high catalytic 
activity for the allylic oxidation of cyclohexene in the absence of solvent with a high selectivity of $81 \%$ to 2 -cyclohexen-1-one at a conversion of $100 \%$ [10], and the $\mathrm{Cu}$-[cationic salphen][ $\left.\mathrm{Br}^{-}\right]_{2}$ complex presented a selectivity of $64.1 \%$ to 2 -cyclohexen-1-one at a $100 \%$ conversion for the aerobic oxidation of cyclohexene in acetonitrile [11]. Although these homogeneous catalysts are efficient for the selective allylic oxidation of cyclohexene, their industrial application is limited due to the difficult separation, and the residual metal ions will affect the quality of the product. Hence, heterogeneous catalysts have been developed by immobilizing metal complexes on solid supports, such as resinate-immobilized Co(II), which exhibited high catalytic activity with a $44.4 \%$ selectivity to 2 -cyclohexen-1-one at a $94.5 \%$ conversion of cyclohexene [12]. Core-shell type $\mathrm{Fe}_{3} \mathrm{O}_{4} @$ @hitosan-Schiff base-immobilized $\mathrm{Co}$ (II), $\mathrm{Cu}$ (II) and $\mathrm{Mn}$ (II) complexes were also reported active for the cyclohexene oxidation, and a selectivity of $77.2 \%$ to 2 -cyclohexen-1-one was obtained at a conversion of $46.8 \%$ [13]. On the other hand, the supported transition metal or oxides were also employed as heterogeneous catalysts for the allylic oxidation of cyclohexene [6,14-20]. Recently, Au nanoparticles supported on modified bentonite and silica gave a high conversion (92\%) and an excellent selectivity (97\%) to 2-cyclohexen-1-one in the aerobic oxidation of cyclohexene without solvent [21]. It was also reported that PdO/SBA-15 was an active catalyst for the oxidation of cyclohexene in acetonitrile, and a conversion of $56 \%$ and a selectivity of $82 \%$ to 2-cyclohexen-1-one were obtained [6]. In addition, nitrogen-doped carbon nanotubes, and graphitic carbon nitride-supported $\mathrm{FeO}$ and $\mathrm{CoO}$ were also effective catalysts for the oxidation of cyclohexene [14,22]. Until now, it was still a hot topic to design a heterogeneous catalyst for the aerobic allylic oxidation of cyclohexene.

In our previous work, we found that Ti-Zr-Co metallic catalyst was effective for the oxidation of cyclohexane and ethylbenzene [23-25], in which cyclohexanol and cyclohexanone were produced with a high selectivity of $90 \%$ at a conversion around $7 \%$, and acetophenone was produced with a $69.2 \%$ selectivity at a high conversion of $61.9 \%$. The Ti-Zr-Co metallic catalyst is simple and cheap in production and sturdy to wearing in the utilization, as compared to those reported catalysts such as metal-organic complex, metal nanoparticles and nanocarbon materials. Therefore, it inspires us to study its efficiency in catalyzing other hydrocarbon oxidations. In the present work, the catalytic performances of the Ti-Zr-Co catalysts were discussed for the aerobic oxidation of cyclohexene. We found that 2-cyclohexen-1-one was produced with a high selectivity of $57.6 \%$ at a conversion of $92.2 \%$, which are comparable to the best results reported for the aerobic oxidation of cyclohexene over heterogeneous catalysts. It was confirmed the surface $\mathrm{CoO}$ and $\mathrm{Co}_{3} \mathrm{O}_{4}$ acted as the catalytic active sites and contributed to the excellent conversion and selectivity.

\section{Results and Discussion}

For the oxidation of cyclohexene, it is very difficult to control product selectivity due to the existence of the two active groups of the $\mathrm{C}-\mathrm{H}$ bond at the allylic site and the $\mathrm{C}=\mathrm{C}$ bond, as when the $\mathrm{C}-\mathrm{H}$ bond is oxidized, 2-cyclohexene-1-ol, 2-cyclohexene-1-one or cyclohexene hydroperoxide will be generated; as the $\mathrm{C}=\mathrm{C}$ bond is oxidized, cyclohexene oxide, cyclohexanol, cyclohexanone, cyclohexanediol and dialdehyde will be produced (Scheme 1) [26].

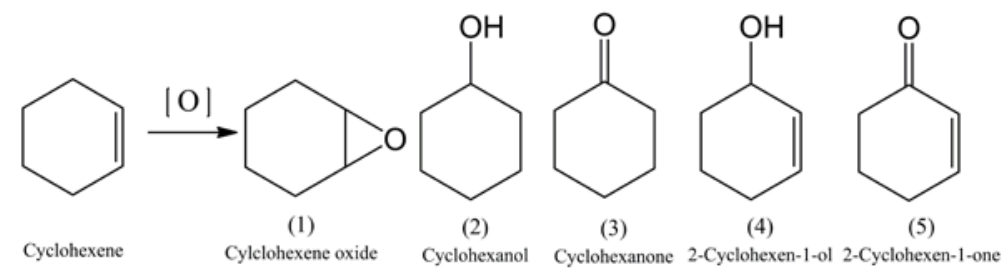

Scheme 1. Reaction route for the aerobic oxidation of cyclohexene.

Firstly, we examined several organic solvents for the oxidation of cyclohexene and the results are listed in Table 1. Among the examined solvents, acetone and acetonitrile are more effective, 
and the higher conversion and selectivity of 2-cyclohexen-1-one were obtained; in contrast, ethanol and cyclohexane are less efficient. However, it was found that acetone could be oxidized (to 2,2-diethoxypropane) during the reaction. As a result, acetonitrile is a suitable solvent which led to a conversion of cyclohexene of $38.0 \%$ and a selectivity to 2-cyclohexen-1-one of $60.6 \%$. Therefore, the acetonitrile was selected as solvent in the following studies.

Table 1. Effect of solvent on the oxidation of cyclohexene over $\mathrm{Ti}_{60} \mathrm{Zr}_{10} \mathrm{Co}_{30}$ catalyst.

\begin{tabular}{cccccccc}
\hline \multirow{2}{*}{ Solvent } & \multirow{2}{*}{ Conversion (\%) } & \multicolumn{6}{c}{ Selectivity (\%) } \\
\cline { 3 - 8 } & & $\mathbf{( 1 )}$ & $\mathbf{( 2 )}$ & $\mathbf{( 3 )}$ & $\mathbf{( 4 )}$ & $\mathbf{( 5 )}$ & Others $^{\mathbf{b}}$ \\
\hline Acetone & 43.9 & 7.3 & 0 & 1.5 & 13.3 & 71.8 & 6.1 \\
Acetonitrile & 38.0 & 3.0 & 0.4 & 1.4 & 13.6 & 60.6 & 21.0 \\
Ethanol & 22.0 & 1.4 & 0 & 0.3 & 4.7 & 25.0 & $68.6^{\mathrm{c}}$ \\
Cyclohexane & 6.2 & - & 0.2 & 7.4 & 9.9 & 37.8 & $44.7^{\mathrm{d}}$ \\
\hline
\end{tabular}

Reaction conditions: cyclohexene $1 \mathrm{~mL}$ (at a concentration of $4.8 \%$ ), solvent $20 \mathrm{~mL}, \mathrm{Ti}_{60} \mathrm{Zr}_{10} \mathrm{Co}_{30} 20 \mathrm{mg}, \mathrm{O}_{2}$ $2 \mathrm{MPa}, 100{ }^{\circ} \mathrm{C}, 12 \mathrm{~h} .{ }^{\mathrm{a}}$ (1) cyclohexene oxide; (2) cyclohexanol; (3) cyclohexanone; (4) 2-cyclohexen-1-ol; (5) 2-cyclohexen-1-one; ${ }^{b}$ Others may consist of reaction intermediate such as cyclohexene hydrogen peroxide, deeply oxidized products such as some ring-opening acids or the byproduct from solvent reacting with substrate. ${ }^{c}$ The ethanol was oxidized into acetic acid and ethyl acetate. ${ }^{\mathrm{d}}$ A certain amount of cyclohexane was found to be oxidized to cyclohexanol and cyclohexanone. The result could not exact calculated.

Next, the reaction conditions were evaluated for the oxidation of cyclohexene in acetonitrile. The results for the effect of the concentration of cyclohexene are shown in Table 2. The conversion of cyclohexene increased significantly with the concentration of cyclohexene; it increased from $33.8 \%$ to $97.5 \%$ when the cyclohexene concentration was raised from $4.8 \%$ to $13.0 \%$. However, the selectivity to 2-cyclohexen-1-one decreased linearly due to deep oxidation of 2-cyclohexen-1-one to undesired byproducts at a higher conversion. The aerobic oxidation of cyclohexene is a radical reaction; it contains the chain-initiation,-propagation and -termination steps [1]. The produced radical in the initial step could promote the following steps and was more efficient at higher cyclohexene concentrations as it enhanced the impact probability of radicals, resulting in an increase of the conversion of cyclohexene. It is notable that when the concentration of cyclohexene increased to $16.7 \%$, the reaction became very violent with a sharp increase of pressure (up to $10 \mathrm{MPa}$ at $3.3 \mathrm{~h}$ ); for safety, the concentration of cyclohexene was controlled below $16.7 \%$ under the present reaction conditions.

Table 2. Effect of the cyclohexene concentration on the oxidation reaction.

\begin{tabular}{|c|c|c|c|c|c|c|c|c|c|}
\hline \multirow{2}{*}{ Entry } & \multirow{2}{*}{ Cyclohexene (\%) } & \multirow{2}{*}{ Time (h) } & \multirow{2}{*}{ Conversion $(\%)$} & \multicolumn{6}{|c|}{ Selectivity (\%) } \\
\hline & & & & (1) & (2) & (3) & (4) & (5) & Others $b$ \\
\hline 1 & 4.8 & 5 & 33.8 & 3.1 & - & 1.7 & 19.1 & 71.3 & 4.9 \\
\hline 2 & 9.1 & 5 & 67.0 & 5.5 & - & 0.7 & 11.6 & 62.5 & 19.8 \\
\hline 3 & 13.0 & 5 & 97.5 & - & - & 0.6 & 3.7 & 49.5 & 46.1 \\
\hline $4^{c}$ & 16.7 & 3.3 & 92.8 & 1.9 & 0.9 & 1.4 & 6.2 & 30.2 & 59.4 \\
\hline
\end{tabular}

Reaction conditions: acetonitrile $20 \mathrm{~mL}, \mathrm{Ti}_{60} \mathrm{Zr}_{10} \mathrm{Co}_{30} 20 \mathrm{mg}, \mathrm{O}_{2} 2 \mathrm{MPa}, 120{ }^{\circ} \mathrm{C}$. ${ }^{\text {a }}$ Concentration of cyclohexene $=V_{\text {cyclohexene }} /\left(V_{\text {cyclohexene }}+V_{\text {acetonitrile }}\right) \times 100 \%$; ${ }^{\mathrm{b}}$ Others may consist of reaction intermediate such as cyclohexene hydrogen peroxide, deeply oxidized products such as some ring-opening acids; ${ }^{c}$ When the concentration of cyclohexene reached $16.7 \%$, the reaction proceeded very quickly with a suddenly pressure rising, and the reaction was stopped at $3.3 \mathrm{~h}$ for safety.

It is well known that temperature is one of the most important factors for oxidation reactions. Generally, high temperature is in favor for the oxidation of hydrocarbons. As the results show in Figure 1, the conversion increased from $17.8 \%$ to $98.2 \%$ while the selectivity of 2-cyclohexen-1-one decreased from $70.1 \%$ to $43.7 \%$ with the temperature rising from 80 to $140{ }^{\circ} \mathrm{C}$. Deep oxidation is serious at higher temperatures and undesirable byproducts such as ring-opening acids are produced. The selectivity of cyclohexene oxide, cyclohexanol and cyclohexanone changed slightly, within $5 \%$. 
The optimal temperature was $120^{\circ} \mathrm{C}$, at which a $57.6 \%$ selectivity of 2-cyclohexene-1-one was obtained at a high conversion of $92.2 \%$.



Figure 1. Effect of temperature on the oxidation of cyclohexene. Reaction conditions: acetonitrile $20 \mathrm{~mL}$, cyclohexene $1 \mathrm{~mL}$ (at a concentration of $4.8 \%$ ), $\mathrm{Ti}_{60} \mathrm{Zr}_{10} \mathrm{Co}_{30} 20 \mathrm{mg}, 2 \mathrm{MPa} \mathrm{O}, 12 \mathrm{~h}$.

In addition, the influence of reaction time on the conversion and product selectivity were examined at conditions of $120{ }^{\circ} \mathrm{C}$, a cyclohexene concentration of $9.1 \%$ and an oxygen pressure of $2 \mathrm{MPa}$. As shown in Figure 2, the conversion increased to $96.1 \%$ with extending the reaction time to $8 \mathrm{~h}$. The selectivity of 2-cyclohexen-1-ol and 2-cyclohexen-1-one decreased from $20.3 \%$ to $4.0 \%$ and $68.8 \%$ to $55.3 \%$ due to the formation and accumulation of deep oxidation products with the reaction proceeding. The other products derived from deep oxidation such as the ring-opening acids increased with a selectivity up to $40 \%(8 \mathrm{~h})$ from $6 \%(1 \mathrm{~h})$, and the intermediates such as cyclohexene oxide, cyclohexanol and cyclohexanone changed very little $(<5.5 \%)$.

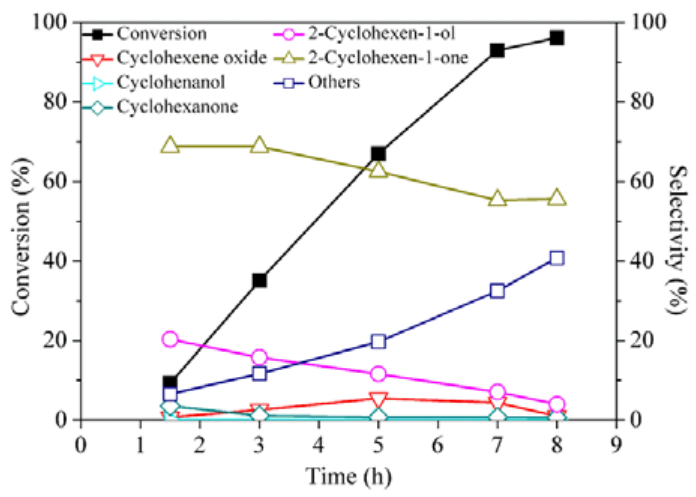

Figure 2. The variation of the conversion and selectivity with extending reaction time. Reaction conditions: cyclohexene $2 \mathrm{~mL}$ (at a concentration of $9.1 \%$ ), acetonitrile $20 \mathrm{~mL}, \mathrm{Ti}_{60} \mathrm{Zr}_{10} \mathrm{Co}_{30}$ $20 \mathrm{mg}, 2 \mathrm{MPa} \mathrm{O}_{2}, 120^{\circ} \mathrm{C}$.

Generally, the aerobic radical oxidation of hydrocarbons can automatically occur in the absence of catalyst [27], but it is very slow and the selectivity of the desired product is poor. The oxidation of cyclohexene can also automatically occur somewhat at certain conditions without catalyst; however, the conversion and selectivity to 2-cyclohexen-1-one are quite low [22]. Herein, we also found that the cyclohexene can convert with a conversion of $14.4 \%$ under the aerobic oxidation conditions without catalyst. As expected, the presence of TiZrCo catalysts can promote the reaction rate significantly as shown in Figure 3. The catalytic performances of TiZrCo catalysts were discussed according to the composition and the surface active species. It is clear that the catalytic activity depends on the Co content in the TiZrCo metallic catalysts, as the conversion of cyclohexene increased to $38.5 \%$ over 
$\mathrm{Ti}_{50} \mathrm{Zr}_{10} \mathrm{Co}_{40}$ from $32 \%$ over $\mathrm{Ti}_{70} \mathrm{Zr}_{10} \mathrm{Co}_{20}$, while the selectivity to 2-cyclohexene-1-one was around $66 \%-69 \%$, and changed very little. These results indicate that the ternary TiZrCo metallic catalysts are effective for the present cyclohexene oxidation, and the content of Co affects the catalytic activity significantly. In order to check the catalytic efficiency of Co species in the present oxidation, $\mathrm{CoTi}_{2}$ and $\mathrm{Co}_{3} \mathrm{O}_{4} / \mathrm{TiO}_{2}$ with the higher content of $\mathrm{Co}$ species were also examined. Unfortunately, both of them gave lower activity compared to the ternary TiZrCo metallic catalysts, as seen in Figure 3. These results suggested not only the Co species but the surface and bulk structure of the TiZrCo catalysts play an important role in the present oxidation. It is assumed that the addition of $\mathrm{Zr}$ may produce surface defects and induce the formation of many more $\mathrm{CoO}$ and $\mathrm{Co}_{3} \mathrm{O}_{4}$ active species.

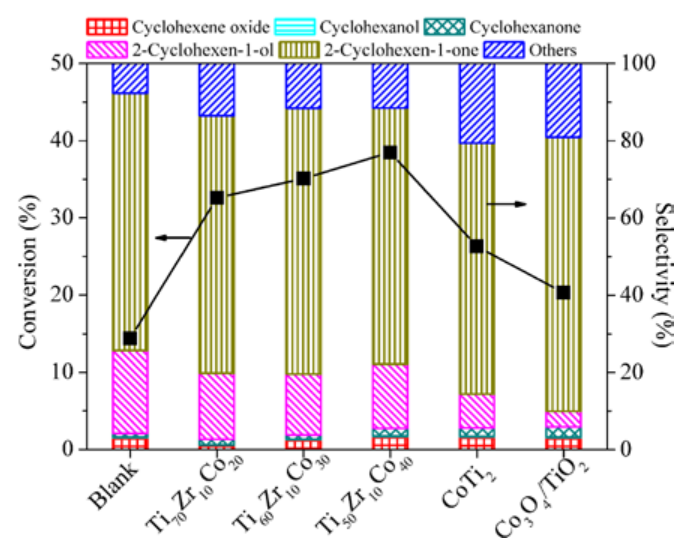

Figure 3. Comparison of the catalytic performances of different catalysts in the oxidation of cyclohexene. Reaction conditions: cyclohexene $2 \mathrm{~mL}$, acetonitrile $20 \mathrm{~mL}$, catalyst $20 \mathrm{mg}, \mathrm{O}_{2} 2 \mathrm{MPa}, 120^{\circ} \mathrm{C}, 3 \mathrm{~h}$.

Therefore, the structure of the TiZrCo catalysts and their relationship to the catalytic performances were discussed. The SEM image of a representative sample of $\mathrm{Ti}_{60} \mathrm{Zr}_{10} \mathrm{Co}_{30}$ is shown in Figure 4a. The size of the particles is at a range of 50-100 $\mu \mathrm{m}$, and the other two samples with different compositions should have a similar morphology as all the samples were crushed and screen-separated by 140 meshes before being examined. The bulk structure of these samples was characterized with XRD as shown in Figure $4 \mathrm{~b}$. For $\mathrm{Ti}_{60} \mathrm{Zr}_{10} \mathrm{Co}_{30}$, with a molar ratio of $\mathrm{Co} / \mathrm{Ti}$ of $1 / 2$, the diffraction patterns are in accordance with the $\mathrm{CoTi}_{2}$ phase without other crystal phases. For $\mathrm{Ti}_{70} \mathrm{Zr}_{10} \mathrm{Co}_{20}$, an I-phase was found beside the $\mathrm{CoTi}_{2}$ phase [28]. However, for $\mathrm{Ti}_{50} \mathrm{Zr}_{10} \mathrm{Co}_{40}$, a new CoTi phase was detected beside the $\mathrm{CoTi}_{2}$ phase.

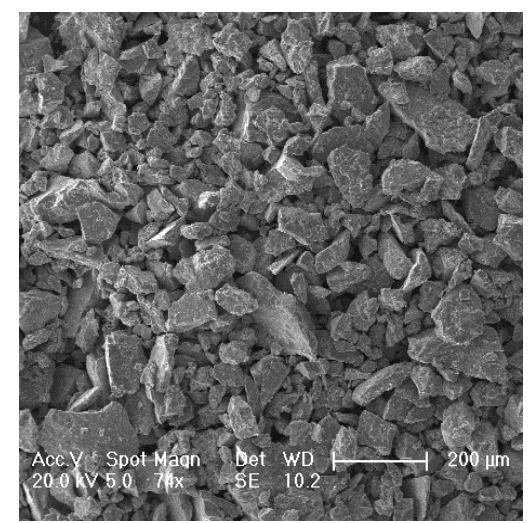

(a)



(b)

Figure 4. The SEM image of $\mathrm{Ti}_{60} \mathrm{Zr}_{10} \mathrm{Co}_{30}$ (a); and the XRD patterns of Ti-Zr-Co catalysts and the JCPDS 07-0141 file identifying $\mathrm{CoTi}_{2}$ (b). 
Therefore, the variation of Co content will impact the bulk structure of TiZrCo significantly, which may have an effect on the catalytic activity. By comparison, the surface species will play a more important role in the catalysis due to the catalytic reaction always occurring on the surface of the heterogeneous catalyst. The surface composition of TiZrCo was studied by XPS. As shown in Figure 5, the $\mathrm{Ti}$ and $\mathrm{Zr}$ existed on the surface with oxidation states of $\mathrm{TiO}_{2}$ and $\mathrm{ZrO}_{2}$, and $\mathrm{Co}$ mainly existed on the surface with metallic $\mathrm{Co}$, oxides of $\mathrm{CoO}$ and $\mathrm{Co}_{3} \mathrm{O}_{4}$, as confirmed by the peak at the binding energy of $777.6 \mathrm{eV}$ and intense shake-up satellites $\mathrm{Co} 2 \mathrm{p}$ XPS spectra around $6 \mathrm{eV}$ above the primary spin-orbit Bes [29-31]; $\mathrm{Co}_{3} \mathrm{O}_{4}$ was confirmed by $\mathrm{Co}^{3+} / \mathrm{Co}^{2+}(2 / 1)$ [32]. The surface compositions calculated according to the results of XPS (Figure 5) are listed in Table 3. To consider the main active species of the Co element, it is clear that all the catalysts contained the same species of $\mathrm{Co}, \mathrm{CoO}$ and $\mathrm{Co}_{3} \mathrm{O}_{4}$ on their surfaces, including $\mathrm{CoTi}_{2}$. The most active $\mathrm{Ti}_{50} \mathrm{Zr}_{10} \mathrm{Co}_{40}$ catalyst contains a higher ratio of $\mathrm{CoO}$ on the surface and different bulk phases, which suggested $\mathrm{CoO}$ may be more effective than the $\mathrm{Co}_{3} \mathrm{O}_{4}$ species, and the bulk phase may be also involved in the present catalysis based on the reaction results in Figure 3. In addition, the surface area of TiZrCo catalysts was also examined, as shown in Table 3; it should have less effect on the present oxidation compared to the surface active species, as the $\mathrm{Ti}_{70} \mathrm{Zr}_{10} \mathrm{Co}_{20}$ with the largest surface area did show a lower conversion, which contains a lower ratio of $\mathrm{CoO}$ and $\mathrm{Co}_{3} \mathrm{O}_{4}$ on the surface.
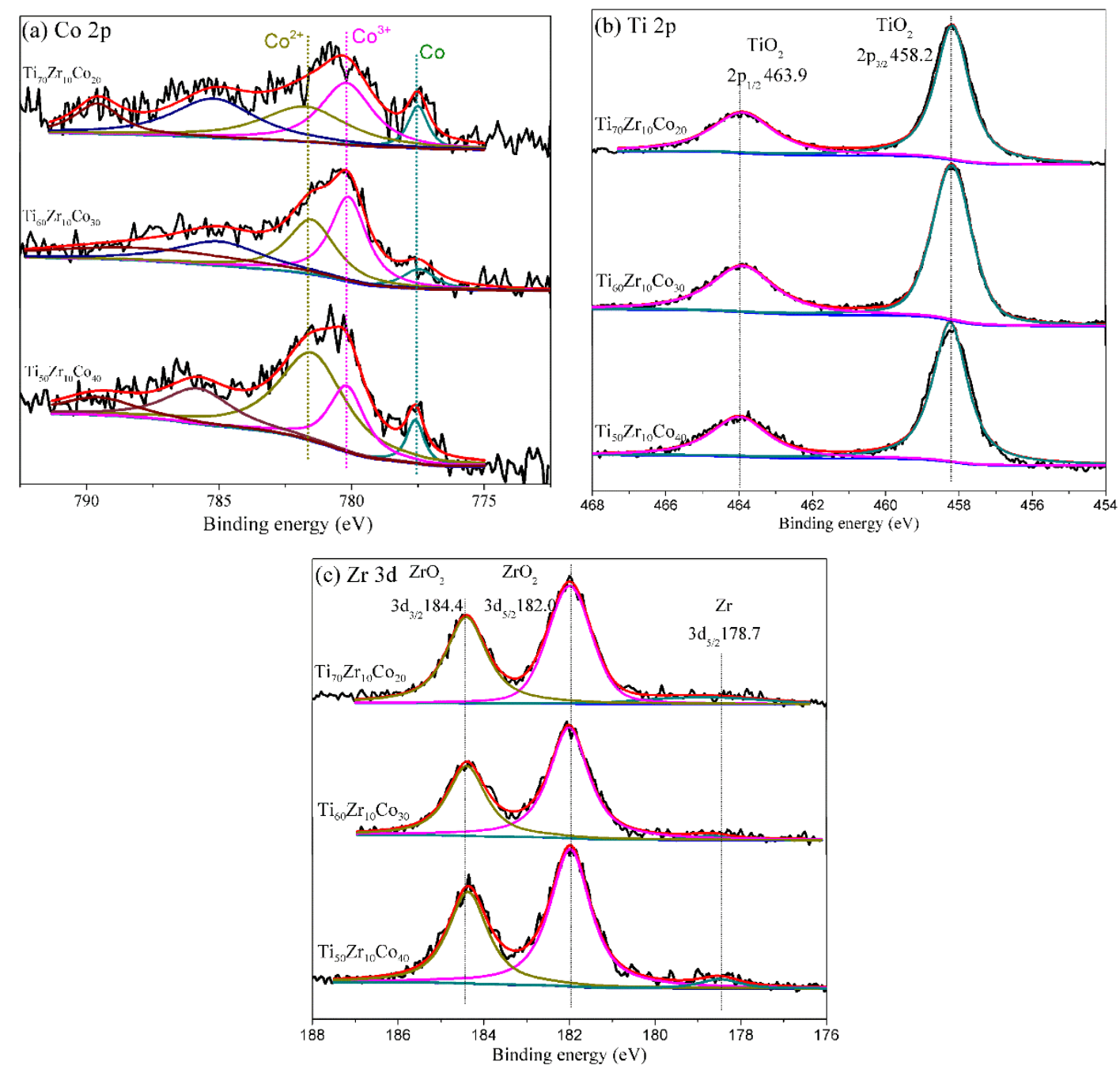

Figure 5. The XPS spectra of (a) Co 2p; (b) Ti 2p and (c) Zr 3d for Ti-Zr-Co catalysts. 
Table 3. Textural and surface properties.

\begin{tabular}{|c|c|c|c|c|c|c|}
\hline \multirow{2}{*}{ Entry } & \multirow{2}{*}{ Catalyst } & \multirow{2}{*}{ Bulk Phase $^{a}$} & \multicolumn{3}{|c|}{ Surface Content of Co (\%) $b$} & \multirow{2}{*}{$S_{\text {BET }}\left(\mathrm{m}^{2} / \mathrm{g}\right)$} \\
\hline & & & Co & $\mathrm{CoO}$ & $\mathrm{Co}_{3} \mathrm{O}_{4}$ & \\
\hline 1 & $\mathrm{CoTi}_{2}$ & $\mathrm{CoTi}_{2}$, I-phase & 31.5 & 37.8 & 30.7 & - \\
\hline 2 & $\mathrm{Ti}_{70} \mathrm{Zr}_{10} \mathrm{Co}_{20}$ & $\mathrm{CoTi}_{2}$, I-phase & 26.9 & 31.2 & 40.9 & 189 \\
\hline 3 & $\mathrm{Ti}_{60} \mathrm{Zr}_{10} \mathrm{Co}_{30}$ & $\mathrm{CoTi}_{2}$ & 20.1 & 32.8 & 47.1 & 70 \\
\hline 4 & $\mathrm{Ti}_{50} \mathrm{Zr}_{10} \mathrm{Co}_{40}$ & $\mathrm{CoTi}_{2}, \mathrm{CoTi}$ & 11.5 & 70.3 & 18.2 & 76 \\
\hline
\end{tabular}

a The bulk phase of the alloy catalysts was obtained based on the XRD patterns; ${ }^{\mathrm{b}}$ The surface composition of the alloy catalysts was calculated from XPS results; ${ }^{\mathrm{c}}$ The surface areas were calculated using the BET equation.

\section{Experimental Section}

\subsection{Ti-Zr-Co Alloy Preparation}

The series of Ti-Zr-Co alloys, as reported in our previous works [25], were prepared by arc-melting of $\mathrm{Ti}(99 \mathrm{wt}$. \%), $\mathrm{Zr}(97 \mathrm{wt}$. \%) and Co (99 wt. \%) metals with a certain mole ratio on a water-cooled cuprum hearth in a high-purity argon atmosphere at $250 \mathrm{~A}$. To make the chemical compositions homogenous, the ingot of alloy was turned over and remelted at least three times. After that, the surface of the cast ingot was burnished in order to eliminate the oxide layer. Then the alloy ingot was crushed by repeated manual beating with a steel pestle and mortar, and the alloy powders were screen separated by 140 meshes.

\subsection{Catalyst Characterization}

The phase composition and microstructure of the alloys were examined by X-ray diffraction (XRD) on a Bruker-AXS D8 ADVANCE (Bruker AXS, Karlsruhe, Germany) with K $\alpha$. The leaching of Ti, Zr or Co in the filtrate was not detected by ICP-OES measurement (iCAP6300, Thermo Waltham, MA, USA). XPS measurements were performed by using a VG Microtech 3000 Multilab. The electronic states of Co 2p, Zr 3d and Ti 2p were determined. All XPS spectra were corrected to the C 1s peak at $284.6 \mathrm{eV}$. Scanning electron microscopy (SEM) image was performed on a Hitachi S-4800 field emission scanning electron microscope (HITACHI, Tokyo, Japan) at an accelerating voltage of $10 \mathrm{kV}$, and the size of particles was in a range of 50-100 $\mu \mathrm{m}$. Nitrogen porosimetry measurement was performed on a Micromeritics ASAP 2020M instrument (Micromeritics, Norcross, GA, USA). The surface areas were calculated using the BET equation.

\subsection{Catalytic Tests}

The catalytic performance was tested in a stainless steel autoclave with a Teflon inner liner (50 mL). Typically, the Ti-Zr-Co catalyst $(20 \mathrm{mg})$, cyclohexene $(2 \mathrm{~mL})$ and acetonitrile $(20 \mathrm{~mL})$ were added. The reactor was then sealed, and placed into an oil bath preset to $120^{\circ} \mathrm{C}$ for $5 \mathrm{~min} . \mathrm{O}_{2}(2 \mathrm{MPa})$ was introduced and the reaction was started with a continuously stirring at $1200 \mathrm{rpm}$. When the reaction finished, the reactor was cooled to room temperature and then depressurized carefully. Then the reaction solution was diluted with ethanol to $50 \mathrm{~mL}$, the composition of reaction products was confirmed by gas chromatography/mass spectrometry (Agilent 5890, Santa Clara, CA, USA) and analyzed with a gas chromatograph (Shimadzu, Kyoto, Japan, GC-2010) equipped with a capillary column (RTX-50, Bellefonte, PA, USA, $30 \mathrm{~m} \times 0.25 \mathrm{~mm} \times 0.25 \mu \mathrm{m}$, carrier: $\mathrm{N}_{2}$ ) and a flame ionization detector (FID).

Safety warning: The use of compressed $\mathrm{O}_{2}$ in the presence of organic substrates requires appropriate safety precautions and must be carried out in suitable equipment. When the pressure decreased far more quickly, the reaction must be stopped immediately. Note, the reaction should be diluted by solvent, otherwise, the blast occur as the reaction is very violent. 


\section{Conclusions}

In summary, TiZrCo catalysts were studied for the first time for the oxidation of cyclohexene. High selectivity $(57.6 \%)$ to 2-cyclohexen-1-one was obtained at a high conversion $(92.2 \%)$ of cyclohexene. $\mathrm{CoO}$ and $\mathrm{Co}_{3} \mathrm{O}_{4}$ on the surface are the main active species and contribute to the high activity and selectivity in the present cyclohexene oxidation. These results indicate that TiZrCo metallic catalysts are effective for the aerobic oxidation of cyclohexene. It is important and significant to extend the studies of the metallic alloy catalyst in catalyzing the aerobic oxidation of hydrocarbons. It is expected that the TiZrCo catalysts may have a broad prospect in industrial applications.

Acknowledgments: The authors gratefully acknowledge the financial support from the One Hundred Talent Program of CAS and Youth Innovation Promotion Association CAS.

Author Contributions: Tong Liu did the experiment and wrote the paper, Haiyang Cheng discussed the results and revised the paper, Chao Zhang, Weiwei Lin, Yancun Yu, Fengyu Zhao supervised this work.

Conflicts of Interest: The authors declare no conflict of interest.

\section{References}

1. Suresh, A.K.; Sharma, M.M.; Sridhar, T. Engineering aspects of industrial liquid-phase air oxidation of hydrocarbons. Ind. Eng. Chem. Res. 2000, 39, 3959-3997. [CrossRef]

2. Thomas, J.M.; Raja, R.; Sankar, G.; Bell, R.G. Molecular sieve catalysts for the regioselective and shapeselective oxyfunctionalization of alkanes in air. Acc. Chem. Res. 2001, 34, 191-200. [CrossRef] [PubMed]

3. Patil, N.S.; Uphade, B.S.; Jana, P.; Bharagava, S.K.; Choudhary, V.R. Epoxidation of styrene by anhydrous $t$-butyl hydroperoxide over reusable gold supported on $\mathrm{MgO}$ and other alkaline earth oxides. J. Catal. 2004, 223, 236-239. [CrossRef]

4. Kuznetsov, M.L.; Rocha, B.G.M.; Pombeiro, A.J.L.; Shul'pin, G.B. Oxidation of olefins with hydrogen peroxide catalyzed by bismuth salts: A mechanistic study. ACS Catal. 2015, 5, 3823-3835. [CrossRef]

5. Wu, H.Y.; Zhang, X.L.; Yang, C.Y.; Chen, X.; Zheng, X.C. Alkali-hydrothermal synthesis and characterization of W-MCM-41 mesoporous materials with various Si/W molar ratios. Appl. Surf. Sci. 2013, 270, 590-595. [CrossRef]

6. Ganji, S.; Bukya, P.; Vakati, V.; Rao, K.S.R.; Burri, D.R. Highly efficient and expeditious PdO/SBA-15 catalysts for allylic oxidation of cyclohexene to cyclohexenone. Catal. Sci. Technol. 2013, 3, 409-414. [CrossRef]

7. Cai, Z.Y.; Zhu, M.Q.; Chen, J.; Shen, Y.Y.; Zhao, J.; Tang, Y.; Chen, X.Z. Solvent-free oxidation of cyclohexene over catalysts with molecular oxygen. Catal. Commun. 2010, 12, 197-201. [CrossRef]

8. Weiner, H.; Trovarelli, A.; Finke, R.G. Expanded product, plus kinetic and mechanistic, studies of polyoxoanion-based cyclohexene oxidation catalysis: The detection of similar to 70 products at higher conversion leading to a simple, product-based test for the presence of olefin autoxidation. J. Mol. Catal. A 2003, 191, 217-252. [CrossRef]

9. Chen, K.X.; Zhang, P.F.; Wang, Y.; Li, H.R. Metal-free allylic/benzylic oxidation strategies with molecular oxygen: Recent advances and future prospects. Green Chem. 2014, 16, 2344-2374. [CrossRef]

10. Zhang, P.F; Gong, Y.T.; Lv, Y.Q.; Guo, Y.; Wang, Y.; Wang, C.M.; Li, H.R. Ionic liquids with metal chelate anions. Chem. Commun. 2012, 48, 2334-2336. [CrossRef] [PubMed]

11. Abdolmaleki, A.; Adariani, S.R. Copper-cationic salphen catalysts for the oxidation of cyclohexene by oxygen. Catal. Commun. 2015, 59, 97-100. [CrossRef]

12. Yin, C.X.; Yang, Z.H.; Li, B.; Zhang, F.M.; Wang, J.Q.; Ou, E.C. Allylic oxidation of cyclohexene with molecular oxygen using cobalt resinate as catalyst. Catal. Lett. 2009, 131, 440-443. [CrossRef]

13. Cai, X.; Wang, H.; Zhang, Q.; Tong, J.; Lei, Z. Magnetically recyclable core-shell $\mathrm{Fe}_{3} \mathrm{O}_{4} @$ chitosan-schiff base complexes as efficient catalysts for aerobic oxidation of cyclohexene under mild conditions. J. Mol. Catal. A 2014, 383, 217-224. [CrossRef]

14. Yang, D.X.; Jiang, T.; Wu, T.B.; Zhang, P.; Han, H.L.; Han, B.X. Highly selective oxidation of cyclohexene to 2-cyclohexene-1-one in water using molecular oxygen over Fe-Co-g- $\mathrm{C}_{3} \mathrm{~N}_{4}$. Catal. Sci. Technol. 2016, 6, 193-200. [CrossRef]

15. Silva, F.P.; Jacinto, M.J.; Landers, R.; Rossi, L.M. Selective allylic oxidation of cyclohexene by a magnetically recoverable cobalt oxide catalyst. Catal. Lett. 2011, 141, 432-437. [CrossRef] 
16. Wang, L.; Wang, H.; Hapala, P.; Zhu, L.; Ren, L.; Meng, X.; Lewis, J.P.; Xiao, F.S. Superior catalytic properties in aerobic oxidation of olefins over Au nanoparticles on pyrrolidone-modified SBA-15. J. Catal. 2011, 281, 30-39. [CrossRef]

17. Donoeva, B.G.; Ovoshchnikov, D.S.; Golovko, V.B. Establishing a au nanoparticle size effect in the oxidation of cyclohexene using gradually changing Au catalysts. ACS Catal. 2013, 3, 2986-2991. [CrossRef]

18. Ghiaci, M.; Dorostkar, N.; Victoria Martinez-Huerta, M.; Fierro, J.L.G.; Moshiri, P. Synthesis and characterization of gold nanoparticles supported on thiol functionalized chitosan for solvent-free oxidation of cyclohexene with molecular oxygen. J. Mol. Catal. A 2013, 379, 340-349. [CrossRef]

19. Zhou, L.; Lu, T.; Xu, J.; Chen, M.; Zhang, C.; Chen, C.; Yang, X.; Xu, J. Synthesis of hierarchical MeAPO-5 molecular sieves-catalysts for the oxidation of hydrocarbons with efficient mass transport. Microporous Mesoporous Mater. 2012, 161, 76-83. [CrossRef]

20. Sang, X.X.; Zhang, J.L.; Wu, T.B.; Zhang, B.X.; Ma, X.; Peng, L.; Han, B.X.; Kang, X.C.; Liu, C.C.; Yang, G.Y. Room-temperature synthesis of mesoporous $\mathrm{CuO}$ and its catalytic activity for cyclohexene oxidation. RSC Adv. 2015, 5, 67168-67174. [CrossRef]

21. Nejad, M.S.; Ghasemi, G.; Martinez-Huerta, M.V.; Ghiaci, M. Synthesis and characterization of Au nanocatalyst on modifed bentonite and silica and their applications for solvent free oxidation of cyclohexene with molecular oxygen. J. Mol. Catal. A 2015, 406, 118-126. [CrossRef]

22. Cao, Y.; Yu, H.; Peng, F.; Wang, H. Selective allylic oxidation of cyclohexene catalyzed by nitrogen-doped carbon nanotubes. ACS Catal. 2014, 4, 1617-1625. [CrossRef]

23. Hao, J.M.; Wang, J.Y.; Wang, Q.; Yu, Y.C.; Cai, S.X.; Zhao, F.Y. Catalytic oxidation of cyclohexane over Ti-Zr-Co catalysts. Appl. Catal. A 2009, 368, 29-34. [CrossRef]

24. Hao, J.M.; Liu, B.Z.; Cheng, H.Y.; Wang, Q.; Wang, J.Y.; Cai, S.X.; Zhao, F.Y. Cyclohexane oxidation on a novel $\mathrm{Ti}_{70} \mathrm{Zr}_{10} \mathrm{Co}_{20}$ catalyst containing quasicrystal. Chem. Commun. 2009, 3460-3462. [CrossRef] [PubMed]

25. Liu, T.; Cheng, H.Y.; Sun, L.S.; Liang, F.; Zhang, C.; Ying, Z.; Lin, W.W.; Zhao, F.Y. Synthesis of acetophenone from aerobic catalytic oxidation of ethylbenzene over Ti-Zr-Co alloy catalyst: Influence of annealing conditions. Appl. Catal. A 2016, 512, 9-14. [CrossRef]

26. Dapurkar, S.E.; Kawanami, H.; Komura, K.; Yokoyama, T.; Ikushima, Y. Solvent-free allylic oxidation of cycloolefins over mesoporous CrMCM-41 molecular sieve catalyst at $1 \mathrm{~atm}$ dioxygen. Appl. Catal. A 2008, 346, 112-116. [CrossRef]

27. Hermans, I.; Jacobs, P.A.; Peeters, J. Understanding the autoxidation of hydrocarbons at the molecular level and consequences for catalysis. J. Mol. Catal. A 2006, 251, 221-228. [CrossRef]

28. Kim, W.J.; Kelton, K.F. Icosahedral-phase formation and stability in Ti Zr Co alloys. Philos. Mag. Lett. 1996, 74, 439-448. [CrossRef]

29. Kim, D.H.; Lee, S.Y.; Jin, J.E.; Kim, G.T.; Lee, D.J. Electrical conductivity enhancement of metallic single-walled carbon nanotube networks by CoO decoration. Phys. Chem. Chem. Phys. 2014, 16, 6980-6985. [CrossRef] [PubMed]

30. Barreca, D.; Massignan, C.; Daolio, S.; Fabrizio, M.; Piccirillo, C.; Armelao, L.; Tondello, E. Composition and microstructure of cobalt oxide thin films obtained from a novel cobalt(ii) precursor by chemical vapor deposition. Chem. Mater. 2001, 12, 588-593. [CrossRef]

31. Dupin, J.C.; Gonbeau, D.; Vinatier, P.; Levasseur, A. Systematic XPS studies of metal oxides, hydroxides and peroxides. Phys. Chem. Chem. Phys. 2000, 2, 1319-1324. [CrossRef]

32. Todorova, S.; Kolev, H.; Holgado, J.P.; Kadinov, G.; Bonev, C.; Pereñíguez, R.; Caballero, A. Complete n-hexane oxidation over supported Mn-Co catalysts. Appl. Catal. B 2010, 94, 46-54. [CrossRef]

(C) 2016 by the authors; licensee MDPI, Basel, Switzerland. This article is an open access article distributed under the terms and conditions of the Creative Commons by Attribution (CC-BY) license (http:/ / creativecommons.org/licenses/by/4.0/). 